\title{
RELATO DE EXPERÊNCIA
}

\section{O USO DE JOGO NO ENSINO DE MATEMÁTICA: UMA POSSIBILIDADE}

\author{
ANA PAULA DE OLIVEIRA VEIGA FAGUNDES* \\ ESTELA SANT'ANNA DE FREITAS GUIMARÃES** \\ GABRIELA HUNSCHE WEINSCHENCK*** \\ SONIA MARIA PEREIRA VIDIGAL****
}

\begin{abstract}
RESUMO
Neste relato de experiência, pretende-se apresentar uma prática pedagógica criada para a disciplina "Didáticas para o Ensino de Matemática" no curso de pedagogia do Instituto Singularidades. A elaboração de tal prática iniciou com a reflexão do ensino por competências e a análise de tais competências e respectivas habilidades propostas na Base Nacional Comum Curricular. Em seguida, fundamentou-se teoricamente a utilização de jogo como uma estratégia pedagógica, para então ser criado um jogo intitulado "Se movimentando com frações", cujo público alvo são
\end{abstract}

* Estudante de bacharelado e licenciatura em Letras-Português e Linguística na Universidade de São Paulo e de Pedagogia no Instituto Singularidades. Já realizou uma Iniciação Científica na área de Linguística e trabalha atualmente com ensino de inglês como segunda língua. Email para contato: ana.fagundes@usp.br

** Ex-aluna da Faculdade Israelita de Medicina Albert Einstein. Atualmente estudante de Pedagogia no Instituto Singularidades. Atua com os Anos Iniciais do Ensino Fundamental. Email para contato: estelasfg@gmail.com *** Formada em Administração de Empresas na PUC-RS e Estudante de Pedagogia no Instituto Singularidades. Atuou na área de compras de empresas varejistas por 20 anos. $\mathrm{Na}$ área da Educação desde 2020. Email para contato: gabriela.weins@gmail.com.br

**** Licenciada em Pedagogia e Matemática. Mestre e Doutora em Educação pela USP, com estágio sanduíche na Universidade de Harvard. Atua com formação de professores e leciona no curso de Pedagogia no Instituto Singularidades. Lattes: 3746413288117760.contato: sonia@singularidades. com.br 
crianças do $5^{\circ}$ ano do Ensino Fundamental. O referido jogo visa sistematizar o aprendizado de frações, especificamente a comparação entre elas. Foram elaboradas também algumas intervenções, de forma a propiciar uma reflexão dos estudantes sobre as possíveis jogadas, com objetivo de pensarem mais profundamente sobre o que aprenderam com o jogo.

Palavras-chave: Ensino de matemática. Jogo. Frações

\begin{abstract}
The purpose of the following experience report is to present a pedagogical practice designed for the subject "Didactics for the teaching of Mathematics" as part of the pedagogy course in Instituto Singularidades. The elaboration of such practice began with the reflection of teaching by competences and the analyses of such competences and related skills proposed in the Base Nacional Comum Curricular (Brazilian common core national standards). Afterwards, the use of games as a pedagogical strategy was theoretically based, and then a game named "Se movimentando com frações" (in a literal translation, "Moving with fractions") was created, whose target audience are fifth-graders. The referred game aims to consolidate the learning of fractions, specifically fractions comparison. Some interventions were also elaborated, in order to propitiate a reflection about the possible plays by the students, with the objective of thinking deeply about what they learned with the game.
\end{abstract}

Keywords: Mathematics teaching, game, fractions

\title{
INTRODUÇÃO
}

A notícia "Alunos da rede estadual usam plataforma de games para estudar matemática" destaca aspectos essenciais em relação ao ensino e aprendizagem de Matemática no mundo atual:

Estudantes do $6^{\circ}$ ano do Ensino Fundamental da rede estadual de ensino passaram a utilizar neste semestre uma plataforma gamificada (jogos) de matemática como com- 
plemento do processo de ensino-aprendizagem. Por meio de jogos interativos e desafios lúdicos, eles trabalham a compreensão de conceitos matemáticos e o desenvolvimento do raciocínio lógico. (AGÊENCIA DE NOTÍCIAS DO PARANÁ, 2021).

Tradicionalmente, o ensino de Matemática era feito por meio da passagem, repetição e cópia de regras, fórmulas e teoremas. Esse tipo de ensino, porém, apresentava diversos problemas. Conforme destaca Pais (2006, p. 28):

Fazer Matemática é uma atividade oposta às práticas de reprodução, as quais consistem em conceber a educação escolar como um exercício de contemplação do mundo científico, de onde vem a ideia de transmissão de conhecimentos.

Na realidade moderna, em que o objetivo da educação é formar seres críticos, autônomos e capazes de atuar na realidade, torna-se claro que o ensino, muito mais do que passar conhecimentos, deve fazer sentido e ser significativo ao aluno, sensibilizando-o e instigando-o a construir conhecimentos.

Nesse movimento, diversos recursos passam a ganhar destaque como ferramentas que podem estimular o processo de ensino aprendizagem. Entre eles, destaca-se o uso de jogos, conforme exemplificado no trecho da notícia acima. O jogo, por seu caráter único e lúdico, apresenta inúmeras vantagens ao processo de ensino aprendizagem, e tem sido cada vez mais explorado em práticas pedagógicas. Nesse contexto, o lúdico, muitas vezes enxergado como exclusivo da primeira infância ou Educação Infantil, também passa a ser cada vez mais valorizado.

Considerando esses aspectos, julgamos importante, na atualidade, pensar em diferentes instrumentos, inclusive digitais, que podem ser utilizados para promover o ensino de Matemática de modo a torná-lo mais significativo aos alunos. 
Partindo desse pressuposto, nós realizamos uma proposta de elaboração de jogo para o $5^{\circ}$ ano do Ensino Fundamental. Esse jogo foi criado como uma das tarefas da disciplina "Didáticas para o Ensino de Matemática”, do curso de Pedagogia do Instituto Singularidades, ministrada pela Prof ${ }^{a}$ Doutora Sonia Vidigal.

Esse relato de experiência será composto, portanto, das diversas considerações que fizemos a respeito do ensino de Matemática até chegarmos à produção de um jogo de frações para o $5^{\circ}$ ano. Primeiramente, será feita uma breve apresentação e justificativa da importância do ensino pautado em competências. Em seguida, o papel dos jogos no processo de ensino aprendizagem será discutido. Por último, apresentaremos a proposta de jogo que criamos e algumas possíveis intervenções que podem ser feitas a partir de tal jogo para garantir uma aprendizagem significativa e duradoura.

\section{ENSINO PAUTADO EM COMPETÊNCIAS}

Atualmente, o ensino baseado em competências tem ganhado destaque nas tendências educativas, estando incluído em importantes documentos legais, como a Base Nacional Comum Curricular (BNCC). Segundo César Coll (2010), competência é a capacidade de responder às exigências individuais ou sociais para realizar uma atividade ou uma tarefa. Segundo Nilson Machado (2009), competência é a capacidade de se mobilizar o que se sabe (o conteúdo) num determinado âmbito (o contexto) para se realizar o que se deseja (o projeto). Segundo ele, o aluno competente é aquele capaz de se expressar, compreender o outro, "ler" o mundo, argumentar usando os conteúdos aprendidos e de tomar decisões, mobilizando o conteúdo que foi estudado. Capaz ainda, de referir o que aprende na escola a contextos específicos múltiplos, e ir além, extrapolando todos os contextos e imaginando aquilo que ainda não existe.

Com base nessas definições, pode-se entender que um ensino baseado em competências envolve articulação e inter- 
-relação de diferentes tipos de conhecimentos. "Assume-se, portanto, a diversidade da natureza psicológica do conhecimento humano; ao identificar e definir as aprendizagens escolares em termos de competências, estamos destacando primeiro a mobilização articulada e inter-relacionada de diferentes conhecimentos" (COLL, 2010, p. 4, grifo nosso). Além disso, o ensino por competências dá grande importância ao contexto em que se adquirem as competências e no qual serão posteriormente aplicadas. Um enfoque baseado na aquisição e no desenvolvimento de competências gerais também permite ensinar aos alunos a transferir o que aprenderam em uma situação concreta para outras situações diferentes. Assim, o ensino por competências permite a realização de aprendizagens significativas, além de funcionais e úteis. Ou seja, o ensino baseado em competências permite uma aprendizagem mais relevante e significativa aos alunos, a partir do uso contextualizado das competências para resolver situações reais de sua vida.

César Coll (2010) ressalta a importância de se considerar o contexto sócio-cultural num mundo caracterizado pela globalização. Ele reforça a relevância de um ensino pautado em competências, citando duas aspirações irrenunciáveis no mundo atual: a de educar os alunos para o exercício de uma "cidadania universal" e a de educá-lo para o exercício de uma cidadania arraigada na realidade social, cultural, nacional e regional da qual faz parte. Assim, o desenvolvimento da competência sempre supõe um fazer. Para o autor, é preciso que o aluno não só assimile e se aproprie dos conhecimentos, mas principalmente que aprenda a mobilizá-los e aplicá-los no seu contexto.

Segundo Nilson Machado (2009), o trabalho com as competências também permite uma maior personalização, não só do que é mais significativo para aquele grupo de alunos, mas também para cada um deles.

Tendo em vista esses aspectos, consideramos que o ensino baseado em competências apresenta diversas vantagens para o ensino dos diversos componentes curriculares. 
Para permitir o desenvolvimento de competências, é essencial refletir sobre a aprendizagem de habilidades que estejam relacionadas a elas. Segundo Perrenoud (2013), habilidades são recursos (saberes práticos) a serviço das competências; ajudam a compô-las. De acordo com a BNCC (BRASIL, 2017, p. 31.), "as habilidades expressam as aprendizagens essenciais que devem ser asseguradas aos alunos nos diferentes contextos escolares". Essas habilidades estão relacionadas a diferentes objetos de conhecimento, que são conteúdos, conceitos ou processos. Assim, também é essencial definir os objetos de conhecimento aos quais essas habilidades estão associadas, pois é através do trabalho com os objetos de conhecimento que as habilidades serão desenvolvidas. Levando em conta esses aspectos, consideramos que o professor deve dar uma enorme importância ao desenvolvimento das habilidades, sem, no entanto, se reduzir a elas.

Segundo Perrenoud (2013), o desenvolvimento de competências exige situações mais complexas do que os exercícios escolares tradicionais, os quais, muitas vezes, criam uma visão em que se acredita que é possível dominar competências graças a uma única habilidade. E sabemos que o domínio de uma única habilidade não é suficiente para resolver um problema.

O que observamos é que o ensino de matemática tende a ser muito focado em memorização de fórmulas e outras informações que os alunos muitas vezes esquecem após algum tempo, enquanto o ensino baseado no desenvolvimento de competências é algo mais duradouro e significativo para a vida das crianças.

Sendo assim, nesse relato de experiência buscaremos refletir sobre um dos recursos possíveis para compor a prática pedagógica do ensino de Matemática e torná-la mais significativa aos alunos: o jogo.

\section{O JOGO NA SALA DE AULA}

Atualmente o uso de jogos na educação tem se tornado cada vez mais comum, sendo justificado pelo seu caráter lúdico e suas possibilidades para uma aprendizagem mais significativa. Segundo Huizinga (1990, p. 16), o jogo “é uma atividade 
que se processa dentro de certos limites temporais e espaciais, segundo uma determinada ordem e um dado número de regras livremente aceitas, e fora da esfera da necessidade ou da utilidade material".

A partir desse trecho, pode-se extrair uma das características mais importantes do jogo: a presença de regras. Segundo Huizinga (1990, p. 14), as regras "são um fator muito importante para o conceito de jogo. Todo jogo tem suas regras. São estas que determinam aquilo que 'vale' dentro do mundo temporário por ele circunscrito". Sendo assim, para jogar um jogo, os participantes devem acordar e aceitar um conjunto de regras, cujo seguimento é condição para participação nessa atividade. Por essa característica, o uso de jogo permite o desenvolvimento de capacidades relacionadas ao convívio social, pois a obediência às regras acordadas é necessária para a continuidade no jogo. Segundo Albuquerque (1953, p. 34), por meio do jogo o indivíduo "deve treinar honestidade, companheirismo, atitude de simpatia ao vencedor ou ao vencido, respeito às regras estabelecidas, disciplina consciente, acato às decisões do juiz[...]".

Outra característica de caráter fundamental do jogo é a interação social que nele ocorre. Para além do estabelecimento e acordo de regras, o jogo envolve intensa interação entre os seus participantes, os quais podem compartilhar estratégias, ajudar uns aos outros e socializar seus conhecimentos. Grando (2004, p. 26) faz as seguintes considerações:

(...) durante o jogo observamos que, muitas vezes, as crianças (adversários) ajudam-se durante as jogadas, esclarecendo regras e, até mesmo, apontando melhores jogadas (estratégias). A competição fica minimizada. O objetivo torna-se a socialização do conhecimento do jogo. Nesse processo de socialização no jogo, a criança ouve o colega e discute, identificando diferentes perspectivas e justificando-se. 
Assim, “o jogo pedagógico tem seu valor reconhecido não apenas pelo aspecto cognitivo, mas também pelos aspectos afetivo e social, ambos importantes para a constituição do sujeito" (RAUPP; GRANDO, 2016, p. 71). Por meio da brincadeira ou do jogo, podem-se obter informações relevantes sobre a criança: "suas emoções, a forma como interage com seus colegas, seu desempenho físico, seu nível linguístico, sua formação moral" (FRIEDMANN, 1996, p. 14), o que pode ser muito útil na prática de um professor.

Segundo Raupp e Grando (2016), jogos auxiliam no desenvolvimento de funções essenciais para o crescimento humano, como a linguagem, a memória, a percepção, a atenção, a motricidade e a formação de relações sociais. Ainda, a caraterística evolutiva do jogo exerce papel importante na evolução do pensamento abstrato das crianças.

Por último, uma importantíssima característica do jogo é a ludicidade. O jogo é uma atividade lúdica, ou seja, uma atividade cuja finalidade é o prazer que a própria atividade oferece. Para Irene Albuquerque (1953, p. 33), o jogo "é uma variedade de exercício que apresenta motivação em si mesma, pelo seu objetivo lúdico". Segundo Grando (2004, p. 8), o exercício de "atividades lúdicas representam uma necessidade para as pessoas em qualquer momento de suas vidas". Entende-se por atividade lúdica aquela cujo fim seja o prazer que a própria atividade oferece.

Ainda, segundo Romão e Brito (2018, p. 18), “divertir-se enquanto aprende e envolver-se com a aprendizagem fazem com que a criança cresça, mude e participe ativamente do processo educativo", além de induzir à criatividade, tão necessária para enfrentar os desafios da vida. De acordo com as autoras, "nos jogos e nas brincadeiras, as crianças transformam os conhecimentos e experiências anteriores em conceitos gerais, com os quais brincam" (ROMÃO; BRITO, 2018, p. 16).

A partir do pensamento de Fiorentini e Morin (1990), que destacam a importância de que os alunos realmente aprendam 
os conteúdos e não somente memorizem, também é possível estabelecer uma relação entre o uso de jogos na educação e a educação por competências, pois como já apontado, o desenvolvimento de competências torna a aprendizagem mais significativa para os alunos, ao permitir que apliquem os conhecimentos e habilidades na prática, e, portanto, vejam a utilidade do que estão aprendendo. Semelhantemente a isso, os jogos trazem vantagens no processo educativo, pois permitem que os alunos apliquem os conhecimentos matemáticos em uma situação prática.

Sendo assim, o jogo, por seu caráter lúdico e social (com estabelecimento e acordo de regras), apresenta diversas vantagens para o ensino, constituindo uma atividade na qual ideias, conhecimentos e estratégias podem ser compartilhados e, portanto, permitindo a aprendizagem conjunta das crianças. A aprendizagem que ocorre por meio do jogo é uma aprendizagem social.

Em relação ao ensino de matemática, Borin (2007) apresenta uma importante justificativa para o uso de jogos nesta área. Segundo ela, o jogo é uma

[...] possibilidade de diminuir os bloqueios apresentados por muitos de nossos alunos que temem a matemática e sentem-se incapacitados para aprendê-la. Dentro da situação de jogo, onde é impossível uma atitude passiva e a motivação é grande, notamos que, ao mesmo tempo em que estes alunos falam matemática, apresentam também um melhor desempenho e atitudes positivas frente a seus processos de aprendizagem. (BORIN, 2007, p. 9)

Dessa maneira, pode-se compreender como a utilização de jogos na educação, inclusive na matemática, pode ser extremamente vantajosa. No entanto, apesar dessas diversas vantagens, alguns cuidados devem ser tomados ao aplicar o jogo como um instrumento pedagógico. De acordo com Fiorentini e Miorim (1990): 
O professor não pode subjugar sua metodologia de ensino a algum tipo de material porque ele é atraente ou lúdico. Nenhum material é válido por si só. (...) A simples introdução de jogos ou atividades no ensino da matemática não garante uma melhor aprendizagem desta disciplina. (FIORENTINI; MIORIM, 1990, p. 4)

Sendo assim, a partir desses autores, pode-se compreender que não se deve inserir o uso de um jogo no ensino simplesmente porque ele é atraente ou "divertido". É claro, o lúdico apresenta diversas vantagens para o processo de aprendizagem, mas esse não deve ser o único motivo para o uso do jogo. Segundo Fiorentini e Miorim (1990, p. 5), "o material mais adequado, nem sempre, será o visualmente mais bonito e nem o já construído. Muitas vezes (...), o mais importante não será o material, mas sim, a discussão e resolução problema ligada ao contexto do aluno, ou ainda, à discussão e utilização de um raciocínio mais abstrato".

O jogo deve ser parte integrante e intencional do planejamento, contendo a definição dos objetivos a serem alcançados e das habilidades que tal jogo permite desenvolver. Também deve partir de situações de resolução de problemas que impliquem a utilização dos princípios lógico matemáticos a serem ensinados. Ainda, na concepção de Moura (1991, p. 49), “o jogo pode, ou não, ser jogo no ensino. Ele pode ser tão maçante quanto a resolução de uma lista de expressões numéricas: perde a ludicidade".

Portanto, pode-se compreender que diversos aspectos devem ser levados em conta antes de aplicar um jogo na educação, de modo a aproveitar o seu pleno potencial, e não o reduzir a simplesmente uma “atividade divertida". É importante não perder de foco sua metodologia de ensino. O cuidado sugerido por Fiorentini e Miorim (1990) é que o professor não entenda os jogos como "solução mágica" para o ensino de matemática; 
segundo eles, nenhum material, por mais lúdico e atraente que seja, é válido por si só.

Como ressaltam os autores, "na verdade, por trás de cada material, se esconde uma visão de educação, de matemática, do homem e do mundo; ou seja, existe, subjacente ao material, uma proposta pedagógica que o justifica" (FIORENTINI; MIORIM, 1990, p. 2).

Considerando as vantagens que o uso de jogos apresenta para o processo de ensino-aprendizagem, nós elaboramos um jogo de matemática para o $5^{\circ}$ ano que explora o conteúdo de frações. Esse jogo, bem como possíveis intervenções a partir dele, será descrito a seguir.

\section{JOGO "SE MOVIMENTANDO COM FRAÇÕES"}

O jogo que criamos terá como público-alvo o $5^{\circ}$ ano dos Anos Iniciais do Ensino Fundamental. Esse jogo ajudará desenvolver algumas competências específicas de Matemática, segundo a BNCC. São elas:

(5) Utilizar processos e ferramentas matemáticas, inclusive tecnologias digitais disponíveis, para modelar e resolver problemas cotidianos, sociais e de outras áreas de conhecimento, validando estratégias e resultados.

(6) Enfrentar situações-problema em múltiplos contextos, incluindo-se situações imaginadas, não diretamente relacionadas com o aspecto prático-utilitário, expressar suas respostas e sintetizar conclusões, utilizando diferentes registros e linguagens (gráficos, tabelas, esquemas, além de texto escrito na língua materna e outras linguagens para descrever algoritmos, como fluxogramas, e dados).

(8) Interagir com seus pares de forma cooperativa, trabalhando coletivamente no planejamento e desenvolvimento de pesquisas para responder a questionamentos e na busca 
de soluções para problemas, de modo a identificar aspectos consensuais ou não na discussão de uma determinada questão, respeitando o modo de pensar dos colegas e aprendendo com eles (BRASIL, 2017, p. 267).

Como inspiração, nos pautamos no jogo "maior ou menor que meio?", presente no livro "Materiais Manipulativos para o Ensino de Frações e Números Decimais", organizado por Kátia Stocco Smole e Maria Ignez Diniz (2016, p. 53), cujas autoras são Ayni Shih, Cláudia Cavalcanti, Ligia Gomes e Sonia Maria Pereira Vidigal. Assim, criamos o jogo "Se movimentando com frações". Partindo da proposta original, expandimos a ideia do jogo "maior ou menor que meio" para "maior ou menor que terço" e "maior ou menor que quarto", incluindo as comparações com estas três frações no interior de um tabuleiro. Acrescentamos ainda outros elementos no tabuleiro para aumentar a jogabilidade.

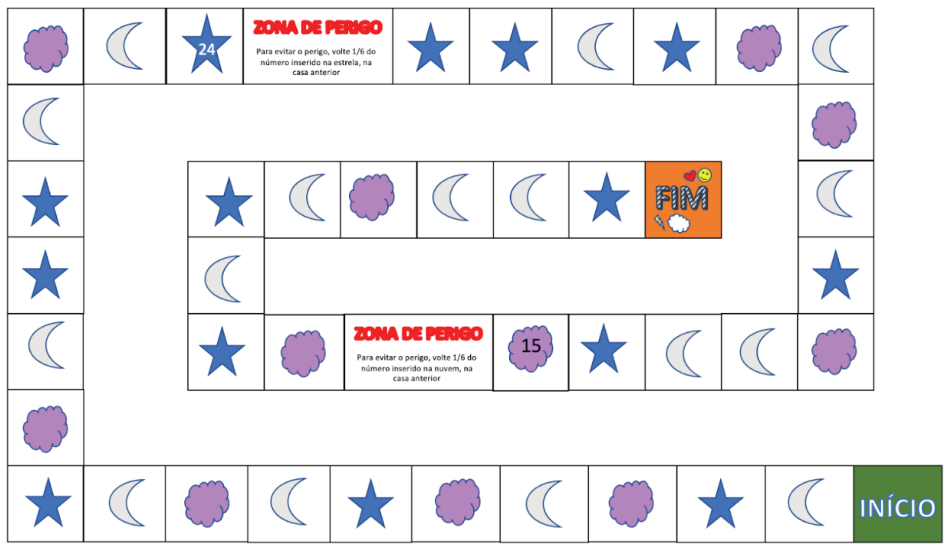

Imagem 1 - Tabuleiro desenvolvido pelas autoras 
O jogo proposto consiste em um jogo de tabuleiro, no qual as "casas" estarão marcadas com um dos três seguintes símbolos: estrela, lua ou nuvem. Se o jogador cair na casa marcada com a estrela, deverá comparar uma fração sorteada com $\frac{1}{3}$. Se o jogador cair na casa marcada com lua, deverá comparar ${ }^{3}$ com $\frac{1}{2} \mathrm{e}$ se cair na casa marcada com nuvem, deverá comparar $\operatorname{com} \frac{1^{2}}{4}$.

As regras estarão apresentadas em três cartas, uma marcảda com estrela, outra com nuvem e outra com lua, de forma que cada uma indique a fração de referência e que a própria criança possa ler suas regras.

O jogo funciona da seguinte maneira: o jogador rodará uma roleta de frações, a qual possui todas as frações possíveis formadas por numeradores de 1 a 6 e denominadores também de 1 a 6. Após sortear a fração, o jogador deve conferir se ela é maior, menor ou equivalente a fração de referência. Se a fração sorteada for maior, o jogador deverá andar 2 casas para frente. Se a fração sorteada for equivalente, ele deverá permanecer na casa em que está; ou seja, não andará para frente nem para trás. Se a fração sorteada for menor, deverá voltar 1 casa. Sendo assim, dependendo da fração sorteada, o jogador pode avançar, ficar estagnado ou retroceder na trilha

Nesse jogo, também há casas nomeadas "Zona de Perigo", dentro das quais estarão escritas instruções que os jogadores devem seguir. Nessas casas, a ideia de fração como "parte-todo" será explorada.

Sugerimos o uso de tiras de fração como material de apoio ao jogo, caso necessário. $\mathrm{O}$ uso desse material é de escolha do/a professor/a, que pode ou não escolher usá-lo de acordo com o andamento/progresso da turma em relação ao conteúdo "frações".

$\mathrm{O}$ uso das tiras pode facilitar o aprendizado ou contribuir para uma revisão ou reforço da equivalência entre frações como entre $\frac{2}{6}$ e $\frac{1}{3}$, por exemplo.

Levando em consideração as características, regras e conteúdo desse jogo, ele auxiliará no desenvolvimento das seguintes habilidades de Matemática, segundo a BNCC (BRASIL, 2017): 
- (EF05MA03) Identificar e representar frações (menores e maiores que a unidade), associando-as ao resultado de uma divisão ou à ideia de parte de um todo, utilizando a reta numérica como recurso.

- (EF05MA04) Identificar frações equivalentes.

- (EF05MA05) Comparar e ordenar números racionais positivos (representações fracionária e decimal), relacionando-os a pontos na reta numérica.

\section{PENSANDO EM INTERVENÇÕES}

Além dos momentos de jogo em si, é preciso que o professor pense em intervenções que potencializem o uso desta ferramenta. Após as crianças jogarem e experimentarem "Se movimentando com frações" algumas vezes, consideramos que seria de extrema importância que o(a) professor(a) fizesse algumas intervenções, de modo a promover reflexões a respeito do jogo e do conteúdo nele envolvido (frações). Sendo assim, sugerimos duas possibilidades de intervenção pós-jogo:

A primeira seria a elaboração de lista de descobertas, dicas e estratégias a respeito do jogo e do conteúdo nele trabalhado.

Nessa primeira intervenção, o objetivo é que as crianças elenquem, em uma lista, descobertas que fizeram a respeito do jogo e do conteúdo nele trabalhado, incluindo dicas ou estratégias que podem aiudar a perceber se a fração é maior, menor ou equivalente a $\frac{1}{2}, \frac{1}{3}$ ou $\frac{1}{4}$. Para a elaboração dessa lista, a turma pode ser dividida em pequenos grupos, sendo cada um deles responsável por fazer uma pequena lista das descobertas que fizeram durante o jogo ou estratégias que utilizaram para potencializar suas jogadas. As informações, dicas, descobertas e estratégias que serão levantadas pelas crianças nessa lista variam de acordo com cada turma. Sendo assim, não é possível prever que conhecimentos as crianças trarão nesse momento. Porém, é possível imaginar que algumas descobertas apareçam, como: 
- Que sempre que o numerador é igual ao denominador representa 1 inteiro e, portanto, a fração sorteada é, com certeza, maior do que a $\frac{1}{2}, \frac{1}{3}$ ou $\frac{1}{4}$ e o jogador anda para frente.

- Que sempre que o numerador é maior do que o denominador, a fração é maior do que um inteiro e, portanto, anda pra frente.

- Quando o numerador é menor que o denominador, temos que ter outra estratégia para comparar as frações.

Depois desse momento inicial de troca entre os alunos nos pequenos grupos, a discussão será trazida para o grande grupo. Nessa discussão, o(a) professor(a) pedirá que as crianças compartilhem o que colocaram em suas listas. De acordo com as informações que forem compartilhadas nesse momento, é interessante a professora ir, aos poucos, fazendo perguntas mediadoras que promovam uma reflexão dos alunos sobre aspectos que eles podem não ter considerado anteriormente e permitam levar a novas descobertas a respeito das frações e do jogo, inclusive contribuindo para a elaboração de estratégias. Algumas perguntas que podem ser feitas (a depender do que a turma já tiver levantado em suas listas), são alguns exemplos:

- Existe alguma estratégia para saber mais rapidamente se a fração obtida é maior do que a de referência (sem usar a ficha de apoio)?

- Como identificamos uma fração equivalente a $\frac{1}{2}, \frac{1}{3}$ ou $\frac{1}{4}$ ?

- Como identificamos se uma fração é equivalente, é menor ou é maior que 1 inteiro?

A segunda intervenção que sugerimos, seria questionar em qual jogo há mais chance de andar para frente.

Nessa intervenção, será trabalhada a seguinte questão: será que existe uma fração de referência que possibilite mais chances 
de andar para frente: maior que $\frac{1}{2}$, maior que $\frac{1}{3}$ ou maior que 1? Por quê?

4 Inicialmente, ao ouvirem esse questionamento, as crianças podem ficar confusas. Sendo assim, em primeiro lugar, é essencial que as regras do jogo sejam retomadas (para essa retomada, sugerimos que a professora pergunte aos alunos quais são as regras, para que eles participem ativamente), de modo que as crianças percebam que, para andar para frente, devemos tirar uma fração maior do que a fração referência. Ou seja, para existir mais chances de andar para frente, deve existir uma das frações de referência com mais probabilidade de tirar uma fração maior que ela. Outras perguntas podem permear esta discussão, uma delas seria questionar com qual fração de referência seria mais vantajoso comparar a fração $\frac{2}{6}$.

A partir de uma reflexão cífica, a professora deve aos poucos expandir a reflexão para algo mais geral e amplo: será que tem uma fração de referência que possibilite mais chances de andar para frente? Para isso, pode dar seguimento com questões como: será que é mais fácil tirar uma fração maior do que $\frac{1}{2}$ ou $\frac{1}{3}$ ? Temos mais chances de tirar uma fração maior do que $\frac{1}{4}^{2}$ ou do que $\frac{1}{2}$ ? Por quê? Nesse momento, é importante refletir que $\frac{1}{4}$ é um número menor que $\frac{1}{2}$, e, portanto, dentro das possibilidades de fração da roleta, existem mais frações maiores que $\frac{1}{4}$ do $\frac{1}{2}$ Para algumas turmas, pode-se montar uma tabela para cada uma das três frações, comparando-as com as da roleta. A partir da tabela, é possível fazer diferentes perguntas para verificar as probabilidades e Até representá-las em forma de razão.

Nessa segunda intervenção, é possível trabalhar com a seguinte habilidade de Matemática, segundo a BNCC (BRASIL, 2017):

- (EF05MA22) Apresentar todos os possíveis resultados de um experimento aleatório, estimando se esses resultados são igualmente prováveis ou não. 


\section{CONSIDERAÇÕES FINAIS}

A fim de cumprir um requisito de uma disciplina do curso de Pedagogia, iniciamos o referido trabalho pensando no ensino baseado em competências e nas possibilidades de uso do jogo na prática docente. Envolvemo-nos com esta proposta não apenas teoricamente, como também elaboramos um jogo que julgamos ser desafiador e divertido. Consideramos que o uso de jogos no ensino da matemática é uma maneira muito eficaz de não só engajar mais os alunos, como também de tornar o processo de aprendizagem mais significativo para eles, uma vez que os alunos se tornam agentes ativos da construção de seu conhecimento, já que estão aplicando-o em uma situação real, como prevê o ensino por competências.

Sendo assim, julgamos que o presente relato tem importância ao ilustrar e compartilhar a possibilidade e a riqueza de estudantes de pedagogia, ainda pouco experientes na área de educação, elaborarem atividades, materiais, jogos, entre outros, que sejam relevantes para os alunos e próprios da prática docente.

Ressaltamos também que ainda não tivemos a oportunidade de aplicar o jogo em sala de aula, e que essa experiência poderá trazer elementos para verificar o potencial do jogo, o quanto ele é atrativo para os alunos e, principalmente, o quanto contribui para o ensino de frações. Destacamos ainda que também achamos ser possível adaptar os princípios de jogabilidade para o ensino de outros conteúdos da matemática.

\section{REFERÊNCIAS}

AGÊNCIA DE NOTÍCIAS DO PARANÁ. Alunos da rede estadual usam plataforma de games para estudar matemática. Paraná, 21 de out. 2021. Disponível em: https://www.aen.pr.gov.br/modules/noticias/article. php? storyid $=116033 \&$ tit=Alunos-da-rede-estadual-usam-plataforma-de- games-para-estudar-matematica. Acesso em: 12 nov. 2021.

ALBUQUERQUE, Irene de. Metodologia da Matemática. Rio de Janeiro: Ed. Conquista, 1953.

BRASIL. Base Nacional Comum Curricular: Educação Infantil e Ensino 
Fundamental. Brasília: MEC/Secretaria de Educação Básica, 2017. Disponível em: http://basenacionalcomum.mec.gov.br/images/BNCC_EI_EF_110518_versaofinal site.pdf. Acesso em: 30 ago. 2021.

BORIN, Júlia. Jogos e resolução de problemas: uma estratégia para as aulas de matemática. São Paulo: IME - US, 2007.

COLL, César. As competências na educação escolar: pouco mais que uma moda e bem menos que um remédio. In: ESPINOZA, Ana Maria; KAUFMAN, Ana Maria; TEBEROSKY, Ana. 30 olhares para o futuro. São Paulo: Escola da Vila, 2010.

FIORENTINI, Dario; MIORIM, Maria Ângela. Uma reflexão sobre o uso de materiais concretos e jogos no Ensino da Matemática. Boletim da SBEM. SBM: São Paulo, ano 4, n. 7, 1990.

FRIEDMANN, Adriana. Brincar: crescer e aprender - o resgate do jogo infantil. São Paulo: Moderna, 1996.

GRANDO, Regina Célia. O jogo e a matemática no contexto de sala de aula. São Paulo: Paulus, 2004.

HUIZINGA, Johan. Homo ludens: o jogo como elemento da cultura. São Paulo: Perspectiva, 1990.

SMOLE, Kátia; DINIZ, Maria Ignez (Orgs.) Materiais manipulativos para o ensino de Frações e Números decimais . Porto Alegre: Penso, 2016.

MACHADO, Nílson José. Educação: competência e qualidade. São Paulo: Escrituras Editora, 2009.

MOURA, Manoel Oriosvaldo de. O jogo e a construção do conhecimento matemático. 1991.

PAIS, Luiz Carlos. Ensinar e Aprender Matemática. Belo Horizonte: Autêntica, 2006.

PERRENOUD, Philippe. Desenvolver Competências ou Ensinar Saberes. Porto Alegre: Penso, 2013.

ROMÃO, Mariluce Ferreira; BRITO, Bonine John Giglio. Dimensões do jogo. Porto Alegre: SAGAH, 2018. 
RAUPP, Andréa Danasceno; GRANDO, Neiva Ignês. Educação matemática: em foco o jogo no processo ensino aprendizagem. In: BRANDT, C.; MORETTI, M., (Orgs). Ensinar e aprender matemática: possibilidades para a prática educativa [online]. Ponta Grossa: Editora UEPG, 2016, pp. 63-83. Disponível em: http://books.scielo.org/id/dj9m9/pdf/brandt-9788577982158-04.pdf. Acesso em: 15 de set. 2021. 